\title{
Nucleotide sequence and characteristics of endoglucanase gene eng $B$ from Clostridium cellulovorans
}

\author{
Frances Foong, Tetsuo Hamamoto, Oded Shoseyov and Roy H. Doi* \\ Department of Biochemistry and Biophysics, University of California, Davis, CA 95616, USA
}

(Received 5 September 1990; revised 13 March 1991; accepted 16 April 1991)

\begin{abstract}
An endoglucanase gene, eng $B$, from Clostridium cellulovorans, previously cloned into pUC19, has been further characterized and its product investigated. The enzyme, EngB, encoded by the gene was secreted into the periplasmic space of Escherichia coli. The enzyme was active against carboxymethylcellulose, xylan and lichenan but not Avicel (crystalline cellulose). The sequenced gene showed an open reading frame of 1323 base pairs and coded for a protein with a molecular mass of $48.6 \mathrm{kDa}$. The mRNA contained a typical Gram-positive ribosomebinding site sequence GGAGG and a sequence coding for a putative signal peptide. There is high amino acid and base sequence homology between the $\mathrm{N}$-terminal regions of EngB and another $C$. cellulovorans endoglucanase, EngD, but they differ significantly in their C-termini. Deletion analyses revealed that up to 32 amino acids of the $\mathrm{N}$-terminus and 52 amino acids of the $\mathrm{C}$-terminus were not required for catalytic activity. The conserved reiterated domains at the C-terminus of EngB were similar to those from endoglucanases from other cellulolytic bacteria. According to our deletion analyses, this region is not needed for catalytic activity.
\end{abstract}

\section{Introduction}

Clostridium cellulovorans is a spore-forming, mesophilic cellulolytic bacterium (Sleat et al., 1984) that can degrade crystalline cellulose. In order to elucidate the mechanism of cellulose degradation by this organism, we have initiated a study to investigate the properties of the subunits of this extracellular cellulase complex (Hamamoto et al., 1990; Shoseyov \& Doi, 1990; Shoseyov et al., $1990)$ and to clone the genes for the subunits. By cloning the genes we plan to analyse their structure and organization, their regulation, their overproduced products and the mechanism of interaction of the subunits with each other and with their solid substrate.

The cellulase complex of clostridia contains many different proteins, including enzymic and non-enzymic subunits (Beguin, 1990; Cavedon et al., 1990; Lamed \& Bayer, 1988; Wood \& Scott, 1988; Wu \& Demain, 1988). A large number of genes have been identified that code for various endoglucanases (Beguin et al., 1985; Grepinet \& Beguin, 1986; Joliff et al., 1986; McGavin \& Forsberg,

Abbreviations: CMC, carboxymethylcellulose; CMCase, carboxymethylcellulase; PCR, polymerase chain reaction; PNPC, PNPG, PNPX, p-nitrophenyl cellobioside, glucoside, xyloside.

The nucleotide sequence data reported in this paper have been submitted to GenBank and have been assigned the accession number M37465.
1988; Shoseyov et al., 1990; Wu \& Demain, 1988). Some of these genes, in the same or different bacterial species, appear to be related, showing domains of conserved amino acid sequences (Faure et al., 1989).

When the cellulase complex is dissociated, the individual subunits may show endoglucanase or cellobiosidase activity, but they are unable to degrade crystalline cellulose. Our working criterion for calling an enzyme a cellulase is that it must be able to degrade crystalline cellulose. We have recently shown that a large $(170 \mathrm{kDa})$ non-enzymic subunit is part of the cellulase complex of C. cellulovorans and is essential for the cellulase activity of the complex (Shoseyov \& Doi, 1990). To obtain a better understanding of the enzymic subunits of the $C$. cellulovorans cellulase complex, we are studying the properties of a number of endoglucanase genes and their enzyme products (Hamamoto et al., 1990; Shoseyov et al., 1990). Here we report the cloning of an endoglucanase gene, eng $B$, from this organism, whose product EngB can hydrolyse a variety of cellulosic substrates, although not crystalline cellulose.

\section{Methods}

Bacterial strains and plasmids. The $C$. cellulovorans endo-1,4- $\beta$ glucanase gene, eng $B$, was cloned in pUC19 as described previously (Shoseyov et al., 1990). Escherichia coli XL1-Blue (BRL) was used as the 
host for the recombinant plasmids $\mathrm{pC} 2$ and $\mathrm{pC} 2$-engB, and for the eng $B$ deletion mutants $\mathrm{N} 1, \mathrm{~N} 2, \mathrm{~N} 3, \mathrm{~N} 4, \mathrm{~N} 5, \mathrm{~N} 6, \mathrm{~N} 7, \mathrm{C} 1, \mathrm{C} 2, \mathrm{C} 3$ and $\mathrm{C} 4$. The vectors pUC19 and pUC18 were used for construction of all recombinant plasmids. E. coli JM101 was used as the host for M13mp18 and M13mp19 vectors for gene sequencing.

Gene sequencing. The dideoxynucleotide method with $\mathrm{M} 13$ single strand template (Maniatis et al., 1982) was used for sequencing engB. The procedure supplied with the sequencing kit, Sequenase Version 2.0 (US Biochemical Corp.) was followed exactly and forward Universal M13 primer was used most frequently; synthesized oligonucleotide primers were used in a few cases. The sequence of both complementary strands was determined.

Cell fractionation. $E$. coli cells harbouring $\mathrm{pC}$-engB were grown to $150 \mathrm{Klett}$ units and isopropyl $\beta$-D-thiogalactoside (IPTG) was added to a final concentration of $1 \mathrm{mM}$. Then the cells were grown to $250 \mathrm{Klett}$ units. The cell suspension was centrifuged and the supernatant (extracellular fraction) was collected, concentrated and assayed for enzymic activity. Activity assays for the deletion clones were performed using total cell extract : the cells were sonicated in PC buffer ( $50 \mathrm{~mm}$-potassium phosphate, $12 \mathrm{~mm}$-sodium citrate, $1 \mathrm{~mm}$-sodium azide), $\mathrm{pH} 6 \cdot 0$, and the supernatant obtained after centrifugation was used for the substrate assay. The osmotic shock method (Neu \& Heppel, 1965) was used to obtain the periplasmic fraction; the osmotically shocked cells were sonicated in $100 \mathrm{~mm}-\mathrm{Tris} / \mathrm{HCl}$ buffer, pH 8.0, 1 mM-phenylmethylsulphonyl fluoride (PMSF) to obtain the cytoplasmic fraction. The fractions were diluted approximately 200 fold and the buffers exchanged with $100 \mathrm{mM}-\mathrm{Tris} / \mathrm{HCl}, \mathrm{pH} 8.0,1 \mathrm{mM}$ PMSF and concentrated with a Centriprep-10 concentrator (Amicon).

Substrate specificity and enzyme assays. The $E$. coli periplasmic fraction was used for substrate specificity assays for the cloned enzyme. Initial testing of carboxymethylcellulase (CMCase), xylanase and lichenanase activity was done on $0 \cdot 1 \%$ carboxymethylcellulose (CMC), xylan or lichenan agar $(1.5 \%)$ plates. Staining with $0.1 \%(\mathrm{w} / \mathrm{v})$ Congo Red and destaining with $1 \mathrm{M}-\mathrm{NaCl}$ was used to visualize the haloes. To test for activity in a strain, the colonies were grown overnight at $37^{\circ} \mathrm{C}$, exposed to chloroform to lyse the cells and incubated for another $6 \mathrm{~h}$ at $37^{\circ} \mathrm{C}$. Then the colonies were washed off with distilled water and the agar plate was stained with $0.1 \%$ Congo Red and destained with $1 \mathrm{M}$ $\mathrm{NaCl}$. CMCase and other substrate activities were quantified by incubating $150 \mu \mathrm{l}$ of the periplasmic fraction with $1.0 \%(\mathrm{w} / \mathrm{v})$ of the appropriate substrate in $\mathrm{PC}$ buffer, $\mathrm{pH} 6.0$, at $37^{\circ} \mathrm{C}$ for $10 \mathrm{~h}$. For the deletion clones, total cell extract was used instead. All the substrates, CMC (sodium salt, medium viscosity), microgranular cellulose, fibrous cellulose (medium), polygalacturonic acid, laminarin, xylan, lichenan, $p$-nitrophenyl $\beta$-cellobioside (PNPC), $p$-nitrophenyl $\beta$-D-glucoside (PNPG) and $p$-nitrophenyl $\beta$-D-xyloside (PNPX) were obtained from Sigma. PNPC, PNPG and PNPX ( $5 \mathrm{~mm})$ were incubated with $150 \mu \mathrm{l}$ of enzyme fraction in PC buffer, pH 6.0.

The amount of reducing sugars obtained at the end of incubation was measured by the Nelson-Somogyi test for reducing sugars (Wood \& Scott, 1988). One unit of activity is defined as $1 \mu \mathrm{mol}$ of reducing sugar liberated (mg protein) ${ }^{-1} \mathrm{~min}^{-1}$. E. coli XL1-Blue containing pUC19 or pUC18 was used as a control in all cases, and the final values were calculated by subtracting the control values. For the $0.1 \% \mathrm{CMC}, 0.1 \%$ SDS $7.5 \%$ denaturing PAGE zymograms, the gels were run and prepared as described before (Shoseyov \& Doi, 1990).
Alkaline phosphatase and malate dehydrogenase activities were measured by the methods of Nisman (1968) and Kitto (1969), respectively. Protein concentration was determined by the BCA Protein Assay System (Pierce).

Construction of recombinant plasmid $p C 2$-eng $B$. Primers were synthesized for the $5^{\prime}$ region of eng $B$, just preceding the putative ribosomebinding site, and for the $3^{\prime}$ region just downstream from the putative stop codon. Sequences for $N c o I$ and EcoRI for the 5' primer (5'-CGGAATTCGGAGGATGAAACCATGGATAAAAGATTATCACGGGGAAAG-3') and BamHI and SmaI for ' 3' primer (5'TTCCCCGGGATCCTCATGGCTCCAGTATACAAGATAACCA-3') were introduced for the bases in the sequence underlined in Fig. 1. Polymerase chain reaction (PCR) amplification using $\mathrm{pC} 2$ template with the synthesized primers were done according to PCR protocols (Innis et al., 1990). The PCR fragment was restricted with EcoRI and $B a m H I$ and cloned into pUC18 to form the recombinant plasmid pC2engB. The insert was checked by restriction with the same enzymes and by one other enzyme internal to the gene.

Construction of deletion mutants. The deletion mutants were constructed either by deleting the amino acid codons from the $5^{\prime}$ or $3^{\prime}$ terminus of eng $B$ with restriction enzymes or by synthesizing primers for the $5^{\prime}$ and $3^{\prime}$ termini with restriction sites and then performing PCR amplification using the pC2-engB template with the synthesized primers. The fragments were restricted with the appropriate restriction enzymes and cloned into either pUC18 or pUC19. The insert was checked by restriction with both enzymes to cleave out the complete fragment and with one other enzyme internal to the fragment to check for the correct fragment sizes.

\section{Results}

\section{Nucleotide sequence of eng $B$}

The $C$. cellulovorans eng $B$ gene was isolated by shotgun cloning of DNA fragments into pUC19 (Shoseyov et al., 1990). An E. coli clone containing a $3 \cdot 2 \mathrm{~kb} C$. cellulovorans chromosomal DNA fragment was found to possess CMCase activity by initial screening on $0.1 \% \mathrm{CMC}$ agar plates stained with Congo Red. The plasmid bearing this fragment was named $\mathrm{pC} 2$. The fragment was subcloned into M13mp18 and M13mp19 for dideoxy sequencing. An open reading frame of 1323 bases was found on this fragment (Fig. 1), which coded for a protein with a molecular mass of $48.6 \mathrm{kDa}$. A putative ribosomebinding site, GGAGG, was found 8 bases upstream of the putative ATG methionine start codon. About 172 bases downstream of the translation stop codon, an imperfect inverted repeat, followed by a stretch of 9 thymidine and 3 adenosine residues, was present which could be the transcript termination signal for the gene since it resembles a rho-independent transcription

Fig. 1. Nucleotide sequence of the $2 \mathrm{~kb}$ DNA fragment which contains eng $B$, and the deduced amino acid sequence of EngB. The putative Shine-Dalgarno sequence GGAGG is overlined. The putative signal peptide in $E$. coli is underlined. The translation termination codon is marked with an asterisk. Palindromic sequences at the 3 ' end of the gene for the possible transcription termination signal are overlined. Primers synthesized for the $5^{\prime}(-13$ to +27$)$ upstream sequence and $3^{\prime}(+1393$ to +1419$)$ downstream sequence of eng $B$ are underlined. 
-399 ATCATACATtatTAAAATCAACTAGACCTATAATCATGC

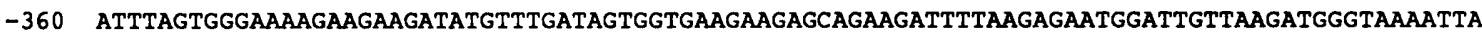

-270 GAgGTAGTCTAGgCTAAACCACTAATAGAAACTCTAAATAATAGTTTTTTCAGAATAAAACCGTTAGAAGgTAAAGTTAGAGgAACTGTT

-180 GTACTAGTGACTAAAAATGCTAGTACTCAGTTTCTTTTTATATTTAGTTTTTTTCACATAAAAATTTTTAGGATAGAATATGgAAAATAT

-90 CCATGTATAGTTCTTTTTTCTCCATATTATCAATGTAATCGGTATGATACCATAAAATGGACAAATAATATATTTTEGAGGATGAAAAA

engB 1 ATGAATAAAAGATTATCACGgGGAAAGATATCTCTTTTAGCATCAGTTTTCGTTACCACAACTTTTATGGGGGGAGTAAATGTTCTCGCA EngB $1 \quad M N R$ B I S R G K I S I L A S V F V T T T F M G G V N V I A

engB 91 TCTACAGCTAAGACAGGTATTCGTGACATAACTTCTCAACAAGTTGTTAAGGAAATGAAGGTTGGTTGGAACTTAGGAAATACAATGGAT

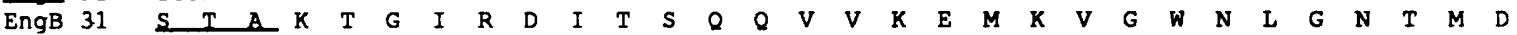

engB 181 GCTACAGgAggAgAAACAAATTGgGgGAATCCATTAACAACACATGCCATGATTGACAAAGTAAAAGCAGCAGgCTTTAATACTTTAAGg

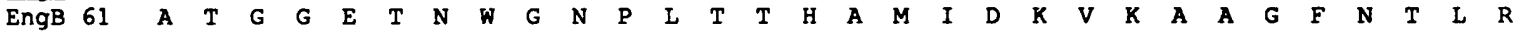

engB 271 CTTCCAATAACTTGgGATgGTCATATTGGAGCAGCACCAGATTATGCTATTGATGCAACATGGATGAATAGAGTCGAAGAAATAGCAAAT \begin{tabular}{lllllllllllllllllllllllllllllllll}
\hline EngB & 91 & L & $P$ & $I$ & $T$ & $W$ & $D$ & $G$ & $H$ & $I$ & $G$ & $A$ & $A$ & $P$ & $D$ & $Y$ & $A$ & $I$ & $D$ & $A$ & $T$ & $W$ & $M$ & $N$ & $R$ & $V$ & $E$ & $E$ & $I$ & $A$ & $N$
\end{tabular}

engB 361 TATGCTTTTGATAATAATATGTATGTTATAATAAATCTTCATCACGAAGATGGATGGCTTAAGCCTTATTATGCCAATGAGGCTGAAGTA

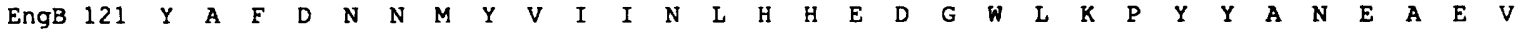

engB 451 AAAGCTAAAATCACAAAAGTATGGACACAAATTGCAAATCGCTTTAAAGATTATGGGGATTATCTAATTTTTGAAACAATGAATGAACCT \begin{tabular}{lllllllllllllllllllllllllllllllll}
\hline EngB & 151 & $K$ & $A$ & $K$ & $I$ & $T$ & $K$ & $V$ & $W$ & $T$ & $Q$ & $I$ & $A$ & $N$ & $R$ & $F$ & $K$ & $D$ & $Y$ & $G$ & $D$ & $Y$ & $L$ & $I$ & $F$ & $E$ & $T$ & $M$ & $N$ & $E$ & $P$
\end{tabular}

engB 541 CGTCCAGTAGGCGCAGCTGATGAATGGTCTGGTGGCTCCTATGAAAATCGAGATATGGTTAATAGATATAATTTAACAGCGGTAAACACT $\begin{array}{llllllllllllllllllllllllllllllll}\text { EngB } & 181 & R & P & V & G & A & A & D & E & W & S & G & G & S & Y & E & N & R & D & M & V & N & R & Y & N & L & T & A & V & N & T\end{array}$

engB 631 ATTAGAgCTACTGGTGGAAATAATGCATTAAGGCACATTATGGTTCCAACTCTTGCAGCAGCAGCACTTAGCACAACAATGAATGATTAC \begin{tabular}{llllllllllllllllllllllllllllllll}
\hline EngB & 211 & I & $R$ & A & T & $G$ & $G$ & N & N & A & L & R & H & I & M & V & P & T & L & A & A & A & A & L & S & T & T & $M$ & M & D & Y
\end{tabular}

engB 721 ATAGTACCAAATAATGATAGCAGAGTTATAGTATCCTTACATATGTATTCACCATATTTCTTCTCTGCAGATCTTACTAGTCAATGGACT

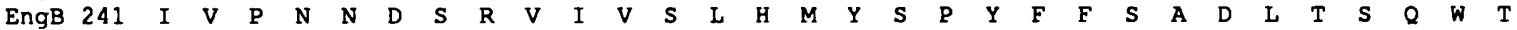

engB 811 ACAGCAACTTGgGGAAGTGATGCTGATAAGGCTGCACTAAGTGCTGACTTTGATGCAGTTTATAATAAGTTTGTTAAGAATGGAAGAGCT \begin{tabular}{lllllllllllllllllllllllllllllllll}
\hline EngB & 271 & $T$ & $A$ & $T$ & $W$ & $G$ & $S$ & $D$ & $A$ & $D$ & $K$ & $A$ & $A$ & $L$ & $S$ & $A$ & $D$ & $E$ & $D$ & $A$ & $V$ & $Y$ & $N$ & $K$ & $F$ & $V$ & $K$ & $N$ & $G$ & $R$ & $A$
\end{tabular}

engB 901 GTAGTTATTGgCGAAATGgGAACAATCAATAAGAATAATTTAGATTCTAGAGTGAAACATCGAGAATATTATGCTAAAGAAGCAACAGTT $\begin{array}{llllllllllllllllllllllllllllllll}\text { EngB } & 301 & V & V & I & G & E & M & G & T & I & N & K & N & N & L & D & S & R & V & K & H & R & E & Y & Y & A & K & E & A & T & V\end{array}$

engB 991 AGAGgGATAACTCCTATATGGTGGGATAATGGATATTGTGTTGCTGGAAAAGAGCAAACCTTCGGAATATTTAATAGAAAGAATCTTACT $\begin{array}{llllllllllllllllllllllllllllllll}\text { EngB } & 331 & R & G & I & T & P & I & W & W & D & N & G & Y & C & V & A & G & K & E & Q & T & F & G & I & F & N & R & K & N & L & T\end{array}$

engB 1081 ACTTGGTGTTGTCCAGAAGTTATGCAAGCTTTCATAAGAGGAGCAGGTGCCACACAAACTCAAACTTCTTATTCACTAGGTGATGTTAAC $\begin{array}{lllllllllllllllllllllllllllllllll}\text { EngB } & 361 & T & W & C & C & P & E & V & M & Q & A & F & I & R & G & A & G & A & T & Q & T & Q & T & S & Y & S & L & G & D & V & N\end{array}$

engB 1171 AAAGATGGAAAGgTAAATGCTATCGATTATGCAGTGCTTAAATCAATTCTTTTAGGTACAAATACTAACGTTGATTTATCAGTATCAGAC $\begin{array}{llllllllllllllllllllllllllllllll}\text { EngB } & 391 & K & D & G & K & V & N & A & I & D & Y & A & V & L & K & S & I & L & L & G & T & N & T & N & V & D & L & S & V & S & D\end{array}$

engB 1261 ATGAATAAGgATgGTAAAGTAAATGCTTTGGATTTAGCTGTTCTTAAAAAAATGCTTTTAAGCTAATGCTTGTACTTGCAAACTTAAATT $\begin{array}{llllllllllllllllllllllllll}\text { EngB } & 421 & M & N & K & D & G & K & V & N & A & L & D & L & A & V & L & K & K & M & L & L & S & *\end{array}$

1351 CTAGTGgGAATATTATAGAATCTTTTAGGTTATAGATGTTAATGGTATCTTGTATACTGGAGCCATGAAAAACTTTGAAAGTTACTAAC 1441 TCTACTAAGGTTAAATATATTTGAAAATGAAAAAATAAATATTTTTATTTAAAGAAATA $\overline{\text { GAGTATCTATAGATTTGATTTTTACAAATCT }}$

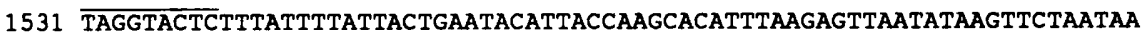




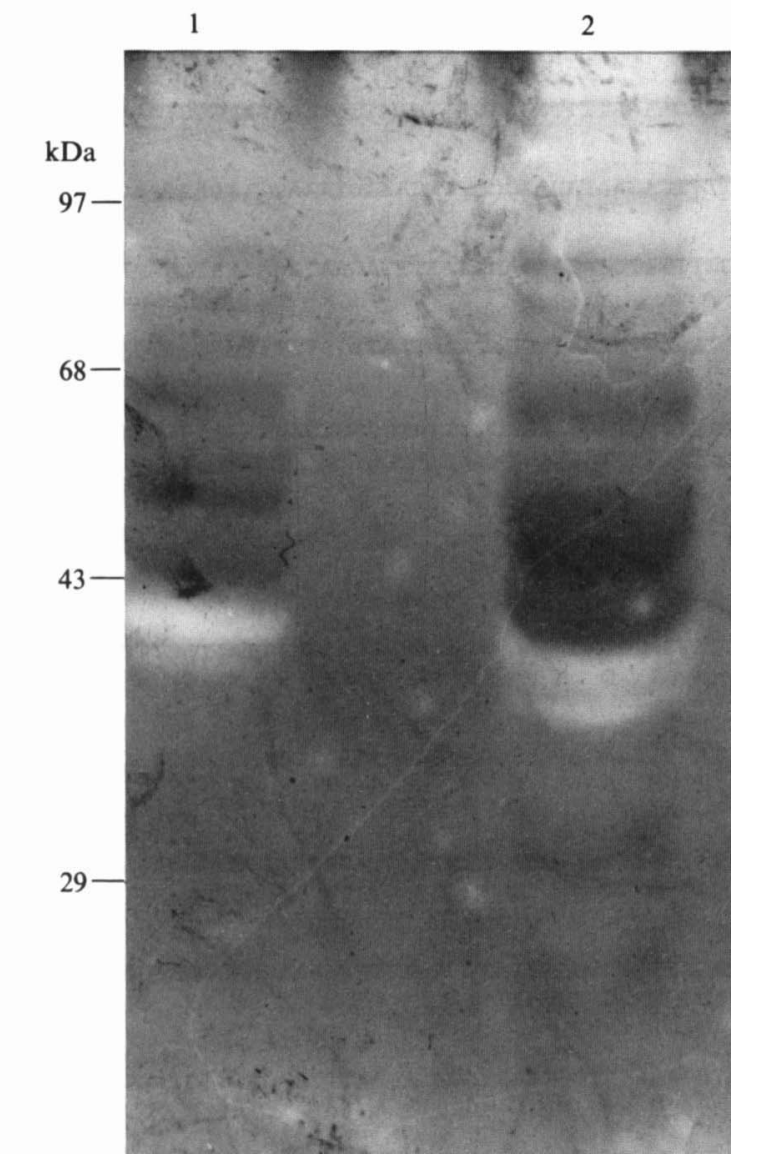

Fig. 2. Zymogram analysis of CMCase activity of the periplasmic fractions of $E$. coli clones pC2-engB (lane 1) and pC2 (lane 2). Molecular mass size markers are shown on the left.

termination signal (Rosenberg \& Court, 1979). The gene sequence was confirmed by subcloning this ORF (pC2engB); the CMCase produced from the subclone had the same molecular mass as that from the original pC2 DNA fragment (Fig. 2). The stretch of 30 amino acids at the Nterminus, from methionine to alanine, with a molecular mass of $3.2 \mathrm{kDa}$ (Fig. 1) conforms to the structure of the $E$. coli signal peptide. The codon usage of the gene has a strong bias $(79.3 \%)$ towards the third nucleotide being either adenosine or thymidine.

\section{Cellular localization of EngB produced in E. coli}

E. coli cells harbouring $\mathrm{pC} 2, \mathrm{pC} 2$-engB or pUC19 as control were grown to 250 Klett units and the cells were harvested and fractionated into extracellular, periplasmic and cytoplasmic fractions for enzyme assays. Cells containing $\mathrm{pC} 2$ or $\mathrm{pC} 2$-engB grew very slowly. CMCase, and the marker enzymes malate dehydrogenase (cytoplasmic) and alkaline phosphatase (periplasmic) were measured in the intracellular, periplasmic and extracellu-
Table 1. Distribution of enzyme activity in the cellular fractions of E. coli( $p C 2$-engB)

Activities were measured as described in Methods. The activity for each cell fraction is expressed as a percentage of the total activity in the three fractions. -, No detectable activity.

\begin{tabular}{lccc}
\hline \hline Cell fraction & CMCase & $\begin{array}{c}\text { Alkaline } \\
\text { phosphatase }\end{array}$ & $\begin{array}{c}\text { Malate } \\
\text { dehydrogenase }\end{array}$ \\
\hline Extracellular & - & $21 \%$ & - \\
Periplasmic & $98 \%$ & $79 \%$ & $45 \%$ \\
Cytoplasmic & $2 \%$ & - & $55 \%$ \\
\hline \hline
\end{tabular}

lar fractions (Table 1). Ninety-eight percent of the CMCase activity was found in the periplasmic fraction, and the remainder in the cytoplasmic fraction. No activity was detected in the extracellular fraction. These results indicated that the EngB protein was probably secreted into the periplasmic space, although the enzyme could also have leaked out into the periplasm because of lysis of the inner cell membrane.

\section{Enzymic properties of EngB}

The DNA fragment which contained the ORF (pC2engB) was amplified by PCR. Initial testing for activity of $\mathrm{pC} 2$-engB and $\mathrm{pC} 2$ clones was done on $\mathrm{CMC}$ plates. The haloes formed after incubation at $37^{\circ} \mathrm{C}$ were exactly the same size for both clones. The control plasmid pUC18 in E. coli XL1-Blue did not produce any halo. When the $1.4 \mathrm{~kb}$ pC2 fragment was cloned in the opposite direction (in pUC19) the halo formed was very much smaller. Since the $1.4 \mathrm{~kb}$ gene fragment did not include any promoter sequences, it is possible that there was readthrough transcription from the vector.

The periplasmic fractions of $\mathrm{pC} 2$ and $\mathrm{pC} 2$-engB clones were run on CMC-SDS-PAGE denaturing gels and the activity bands on the zymogram revealed that both samples produced proteins with a molecular mass around $42 \mathrm{kDa}$ (Fig. 2). The EngB protein was active on CMC, lichenan, and xylan but not on fibrous or microcrystalline cellulose, Avicel, polygalacturonic acid, mannan, laminaran, PNPC, PNPG, or PNPX. This indicated that the enzyme was only active at an endo-glycolytic level and that it probably only cleaved $\beta-1-4$ glycosidic bonds. The specific activity of EngB was 1.2 units for CMCase, $8 \cdot 1$ units for lichenanase and $1 \cdot 1$ units for xylanase.

\section{Activity of the deletion mutants}

Deletions from the $5^{\prime}$ and $3^{\prime}$ termini of eng $B$ indicated that when 24 amino acids (counting from the ATG 


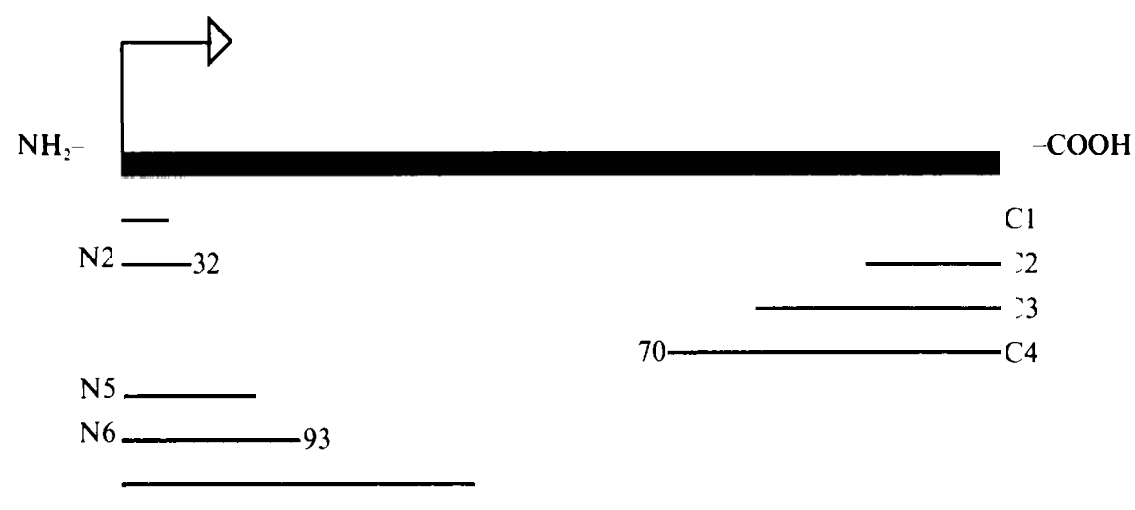

$\begin{array}{lcccccccccccc} & \text { engB } & N 1 & N 2 & N 3 & N 4 & N 5 & N 6 & N 7 & \text { C4 } & \text { C3 } & \text { C2 } & \text { Cl } \\ \text { CMCase } & + & + & + & \pm & - & - & - & - & - & - & \pm & + \\ \text { Xylanase } & + & + & + & \pm & - & - & - & - & - & - & \pm & + \\ \text { Lichenanase } & + & + & + & \pm & - & - & - & - & - & - & \pm & +\end{array}$

Fig. 3. The deletion mutants of engB and their CMCase, xylanase, and lichenanase activities. N1, N2, N3, N4, N5, N6 and N7 are deletion mutants from the $\mathrm{N}$-terminus; $\mathrm{C} 1, \mathrm{C} 2, \mathrm{C} 3$ and $\mathrm{C} 4$ are deletion mutants from the $\mathrm{C}$-terminus. The numbers to the right and left in the upper part of the figure denote the numbers of amino acids that were deleted. Enzyme activities of the mutants are shown in the lower part of the figure: + , positive activity; - , no detectable activity; \pm , residual activity.

methionine start site) were deleted from the N-terminus of the EngB protein, the activity for the substrates CMC, xylan and lichenan was unaffected. When 32 amino acids were deleted there was a slight drop in activity, and when 42 amino acids were deleted, there was only residual activity (Fig. 3). Deletion of 52 amino acids from the C-terminus, removing the conserved, reiterated region of the gene, resulted in no loss of activity. Deletion of up to 71 amino acids from the C-terminus resulted in a low level of residual activity.

\section{Discussion}

The nucleotide sequence of eng $B$ consists of an open reading frame of 1323 bases. By calculation, the gene can code for a protein of $48 \cdot 6 \mathrm{kDa}$. The zymograms of the periplasmic fraction of $E$. coli clones harbouring $\mathrm{pC} 2$ or pC2-engB showed activity bands at approximately $42 \mathrm{kDa}$, indicating that $\mathrm{pC} 2$ and $\mathrm{pC} 2$-engB coded for the same protein. The molecular mass of the product expressed in $E$. coli was $5-6 \mathrm{kDa}$ smaller than the estimated molecular mass of the protein deduced from the gene sequence. Since most of the CMCase activity was found in the periplasmic space, the protein was probably processed by the $E$. coli host and secreted into the periplasmic space.

The zymogram of the native cellulase isolated from the extracellular fluid of C. cellulovorans (Shoseyov \& Doi, 1990) showed enzyme activity bands ranging from 40 to $100 \mathrm{kDa}$, so the cloned gene (eng $B$ ) may code for one of the enzymes of the cellulase complex. Similarities at the amino acid level between EngB and endoglucanase genes from other species range from 30 to $50 \%$ similarity (GCG sequence software package analysis, Madison, Wisconsin; Bestfit for gap and homology alignment) with similarities of $43 \%$ with $C$. thermocellum celA, $50 \%$ with $c e l B$ and $46 \%$ with celD. Most of the homology was found to be at the C-terminus (Fig. 4), where 50-60 residues were highly conserved (Beguin, 1990). The region contains two homologous segments linked by $8-20$ amino acid residues. Similar structures were found in an endoglucanase sequence from $C$. cellulolyticum, egcc $A$ (Faure et al., 1989), and a xylanase gene from $C$. thermocellum, cloxynZ (Hall et al., 1988). The function of these conserved, reiterated regions of homology is unknown (Faure et al., 1989) but it is not essential for catalytic activity (Grepinet et al., 1988; Hall et al., 1988). The truncated $C$. thermocellum enzyme (Chavaux et al., 1990) without its conserved C-terminal region was also very similar to the enzyme, $\mathrm{EgD}$, expressed from the intact gene in terms of activity and calcium-binding effects.

The deletion of 52 amino acids from the $\mathrm{C}$-terminus of C. cellulovorans EngB, which eliminated the conserved, reiterated, region, resulted in no activity loss, thereby confirming reports that it is not needed for catalytic activity. When 71 amino acids were deleted, there was still residual activity, as detected by Congo Red agar plate assay, which was more sensitive than the reducing sugar assay. Perhaps at this point the drop in activity was due to instability of the enzyme rather than to loss of the 


\begin{tabular}{|c|c|c|c|}
\hline Clocela & 386 & 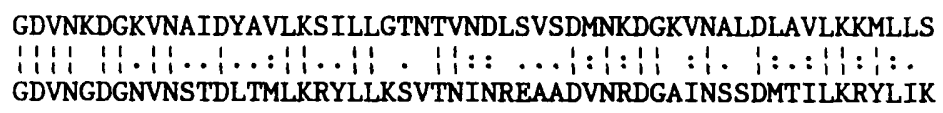 & 440 \\
\hline $\begin{array}{l}\text { EngB } \\
\text { Clocelb }\end{array}$ & 386 & 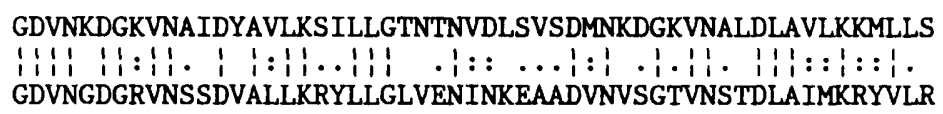 & 440 \\
\hline $\begin{array}{l}\text { EngB } \\
\text { Cloceld }\end{array}$ & $\begin{array}{l}386 \\
583\end{array}$ & 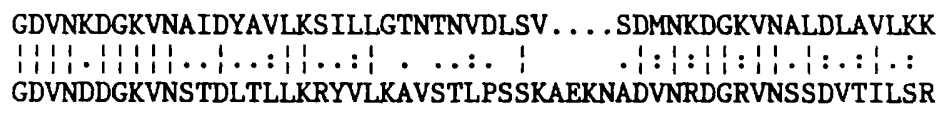 & 637 \\
\hline $\begin{array}{l}\text { EngB } \\
\text { Cloxynz }\end{array}$ & $\begin{array}{l}384 \\
427\end{array}$ & 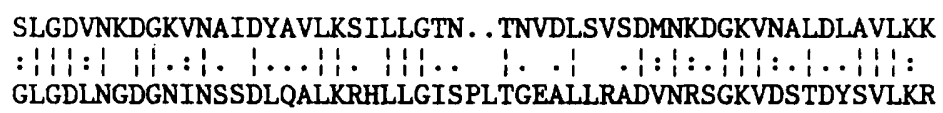 & 436 \\
\hline EngB & 386 & 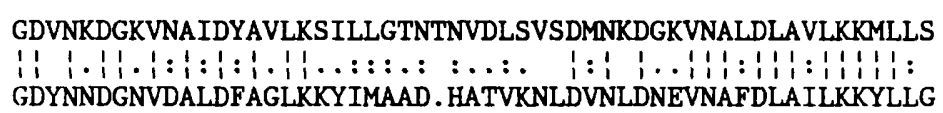 & 440 \\
\hline
\end{tabular}

Fig. 4. Comparison of homologous regions at the C-terminus of EngB with three endoglucanases from C. thermocellum, ClocelA, Cloce1B, Cloce1D; a xylanase from C. thermocellum, CloxynZ; and an endoglucanase from C. cellulolyticum, Egcca. Identical amino acids are indicated with a line, similar amino acids with two dots, and less similar amino acids with one dot. The numbers on the left and right indicate the amino acid positions. These partial amino acid sequences were obtained from the corresponding gene sequences of Cloce1 A (Beguin et al., 1985), Cloce1 B (Grepinet \& Beguin, 1986), Clocel D (Joliff et al., 1986), CloxynZ, and Egcca (Faure et al., 1989).

catalytic site. When 24 amino acids were deleted from the N-terminus, the activity for all three substrates remained the same whereas there was a slight drop in activity when 32 amino acids were deleted. This region can probably be deleted without much effect since this may be the signal peptide of the native enzyme. The secondary structure of the first 30 amino acids (Chou \& Fasman, 1978) of the protein revealed a typical signal peptide (Neuwald \& Stauffer, 1989). Up to 157 bp could be deleted from the $5^{\prime}$ end of the $C$. thermocellum endoglucanase EGE gene without affecting the catalytic activity of EGE produced by E. coli (Hazlewood et al., 1990). However, the full-size enzyme is $75 \mathrm{kDa}$ and the protein was still active when it was proteolytically processed to $40 \mathrm{kDa}$, indicating that a large part of the protein is also not required for catalytic activity. The manner and the ratios in which the activities for the substrates were lost indicated that the catalytic site for the three substrates of EngB is the same.

The eng $B$ gene and EngB product both had high homology $(75 \%)$ at the $5^{\prime}$ end and $\mathrm{N}$-terminus, respectively, with another $C$. cellulovorans endoglucanase gene, eng $D$, and its product EngD (unpublished data). However, there were significant differences between the two gene products at their C-termini and EngB did not contain the 'hinge' region (O'Neill et al., 1986; Wong et al., 1986) present in EngD. The homology between engB and eng $D$ ends at this 'hinge' region. Since catalytic activity was not lost from eng $B$ when nearly all of the Cterminus was deleted, the catalytic site is probably at the $\mathrm{N}$-terminus.

It has been suggested that the conserved, reiterated region may play a role in the interaction between macromolecules carrying reiterated determinants, e.g. the substrate or possibly a scaffolding protein of the cellulosome (Wu \& Demain, 1988). A protein of this sort, of $170 \mathrm{kDa}$, has been purified from $C$. cellulovorans (Shoseyov \& Doi, 1990). It has no enzymic activity but has very strong binding affinity to cellulose. This protein may act as a core protein to which the other catalytic subunits bind to form the cellulase complex, thus aiding in the cooperative action of the enzymes required for digestion of crystalline cellulose. Perhaps the conserved region of EngB interacts with this $170 \mathrm{kDa}$ protein.

The zymogram patterns of $\mathrm{pC} 2$ and $\mathrm{pC} 2$-engB clones both showed the presence of an endoglucanase of around $42 \mathrm{kDa}$. Purified EngB from pC2-engB-containing cells (unpublished data), after being boiled in SDS, run in SDS-PAGE and stained with Coomassie Blue, showed the same molecular mass as that of the enzymes in the zymogram. Since the $1.4 \mathrm{~kb}$ PCR product in pC2-engB contains only the nucleotide sequence of the eng $B$ gene together with its putative RBS, the transcription initiation must be from the lac promoter on the pUC vector, 
although transcription can probably be initiated from a Clostridium promoter sequence by the $E$. coli RNA polymerase (Zappe et al., 1986).

EngB was active against $\mathrm{CMC}$, xylan and lichenan. Several other cloned gene products have been shown to possess activities on multiple substrates (Gilbert et al., 1988; Gilkes et al., 1984; Hamamoto et al., 1990; McGavin \& Forsberg, 1988; Taylor et al., 1987). The substrates that EngB is capable of using all have $\beta-1,4$ glycosyl linkages. The enzyme has very high activity against lichenan, a mixed glucan containing $\beta-1,4$ and $\beta$ 1,3 linkages, but it has no detectable activity against laminarin (predominantly $\beta$-1,3-glycan), indicating that cleavage is predominantly at the $\beta-1,4$ linkages. It also has no activity against Avicel cellulose or PNPC, which is a substrate for cellobiosidase activity, suggesting that this enzyme may need the synergistic action of exoglucanases in order to degrade cellulose effectively. The multiple activities of EngB are beneficial since it is possible for the cellulase complex to contain fewer enzyme species to degrade cellulosic material such as cellulose, hemicellulose (xylans), and lichenan. C. cellulovorans was isolated from a methanogenic digester of poplar wood (Sleat et al., 1984). Perhaps cellulolytic organisms have evolved enzymes of wide specificity which make them capable of digesting several types of substrates found in woody material.

The codon usage of the eng $B$ gene was strongly biased, since $79 \cdot 3 \%$ (342/431 codons) of the third nucleotides were either adenosine or thymidine. This reflects the very low $\mathrm{G}+\mathrm{C}$ content $(26-27 \mathrm{~mol} \%$ ) of $C$. cellulovorans (Sleat et al., 1984).

The eng $B$ gene cassette produced from the PCR reaction contains restriction sites, which facilitates transfer of the gene from one vector to another. This construct should be useful for studying gene regulation and expression, overproduction of the enzyme, and secretion.

This work was supported in part by grant GM 19673 from the National Institute of General Medical Sciences (R.H.D.) and Grant \#DE-FG03-87ER13705 from the Department of Energy (R.H.D). O.S. was supported by fellowship SI-0057-87 from the United StatesIsrael Binational Agricultural Research and Development Fund.

\section{References}

Beguin, P. (1990). Molecular biology of cellulose degradation. Annual Review of Microbiology 44, 219-248.

Beguin, P., CoRnet, P. \& Aubert, J.-P. (1985). Sequence of a cellulase gene of the thermophilic bacterium Clostridium thermocellum. Journal of Bacteriology 162, 102-105.

Cavedon, K., Leschine, S. B. \& Canale-Parola, E. (1990). Cellulase system of a free-living mesophilic Clostridium (Strain C7). Journal of Bacteriology 172, 4222-4230.
Chavaux, S., Beguin, P., Aubert, J.-P., Bhat, K. M., Gow, L. A., WOOD, T. M. \& BAIROCH, A. (1990). Calcium-binding affinity and calcium-enhanced activity of Clostridium thermocellum endoglucanase D. Biochemical Journal 265, 251-265.

Chou, P. Y. \& Fasman, G. D. (1978). Prediction of the secondary structure of proteins from their amino acid sequence. Advances in Enzymology 47, 45-147.

Faure, E., Belaich, A., Bagnara, C., Gaudin, C. \& Belaich, J. P. (1989). Sequence analysis of the Clostridium cellulolyticum endoglucanase-A-encoding gene, celCCA. Gene 84, 39-46.

Gilbert, H. J., Sullivan, D. A., Jenkins, G., Kellett, L. E., Minton, N. P. \& HaLl, J. (1988). Molecular cloning of multiple xylanase genes from Pseudomonas fluorescens subsp. cellulosa. Journal of General Microbiology 134, 3239-3247.

Gilkes, N. R., LaNGSFord, M. L., Kilburn, D. G., Miller, R. C., JR \& Warren, R. A. J. (1984). Mode of action and substrate specificities of cellulases from cloned bacterial genes. Journal of Biological Chemistry 259, 10455-10459.

GREPINET, O. \& BeGUIN, P. (1986). Sequence of the cellulase gene of Clostridium thermocellum coding for endoglucanase B. Nucleic Acids Research 14, 1791-1799.

Grepinet, O., Chebrou, M.-C. \& Beguin, P. (1988). Nucleotide sequence and deletion analysis of the xylanase gene $(x y n Z)$ of Clostridium thermocellum. Journal of Bacteriology 170, 4582-4588.

Hall, J., Hazlewood, G. P., Barker, P. J. \& Gilbert, H. J. (1988). Conserved and reiterated domains in Clostridium thermocellum endoglucanases are not essential for catalytic activity. Gene 69, 29-38.

Hamamoto, T., Shoseyov, O., Foong, F. \& Dol, R. H. (1990). A Clostridium cellulovorans gene, eng $D$, codes for both endo-beta-1,4glucanase and cellobiosidase activities. FEMS Microbiology Letters 72, 285-288

Hazlewood, G. P., Davidson, K., Clarke, J. H., Durrant, A. J., Hall, J. \& Gilbert, H. J. (1990). Endoglucanase E, produced at high level in Escherichia coli as a lac $Z^{\prime}$ fusion protein, is part of the Clostridium thermocellum cellulosome. Enzyme and Microbial Techno$\log y 12,656-662$.

Innis, M. A., Gelfand, D. H., Sninsky, J. J. \& White, T. J. (editors) (1990). PCR Protocols, a Guide to Methods and Application, pp. 320322. New York: Academic Press.

JolifF, G., BÉGUIN, P. \& AUBERT, J. P. (1986). Nucleotide sequence of the cellulase gene celD encoding endoglucanase D of Clostridium thermocellum. Nucleic Acids Research 14, 8605-8613.

KITTO, G. B. (1969). Intra- and extramitochondrial malate dehydrogenase from chicken and tuna heart. Methods in Enzymology 13, 106116.

LAMED, R. \& BAYER, E. A. (1988). The cellulosome concept: exocellular/extracellular enzyme reaction centers for efficient binding and cellulolysis. In Biochemistry and Genetics of Cellulose Degradation, pp. 101-116. Edited by J.-P. Aubert, P. Beguin \& J. Millet. San Diego: Academic Press.

Maniatis, T., Fritsch, E. F. \& Sambrook, J. (1982). Molecular Cloning. A Laboratory Manual. Cold Spring Harbor, NY: Cold Spring Harbor Laboratory.

MCGAVIN, M. \& ForsBerg, C. W. (1988). Isolation and characterization of endoglucanase 1 and 2 from Bacteroides succinogenes S85. Journal of Bacteriology 170, 2914-2922.

Neu, H. C. \& Heppel, L. A. (1965). The release of enzymes from Escherichia coli by osmotic shock and during the formation of sphaeroplasts. Journal of Biological Chemistry 240, 3685-3692.

Neuwald, A. F. \& Stauffer, G. V. (1989). An Escherichia coli membrane protein with a unique signal sequence. Gene 82, 219-228.

Nisman, B. (1968). Techniques for demonstrating DNA-dependent protein synthesis. Methods in Enzymology 12B, 794-820.

O’Neill, G., Goh, S. H., Warren, R. A. J., Kilbern, D. G. \& Miller, R. C., JR (1986). Structure of the gene encoding the exoglucanase of Cellulomonas fimi. Gene 44, 325-330.

ROSENBERG, M. \& COURT, D. (1979). Regulatory sequences involved in the promotion and termination of RNA transcription. Annual Review of Genetics 13, 319-353.

Rouvinen, J., Bergfors, T., Teeri, T., Knowles, J. K. C. \& Jones, T. A. (1990). 3-Dimensional structure of cellobiohydrolase II from Trichoderma reesei. Science 249, 380-385. 
Shoseyov, O. \& DoI, R. H. (1990). Essential 170-kDa subunit for degradation of crystalline cellulose by Clostridium cellulovorans cellulase. Proceedings of the National Academy of Sciences of the United States of America 87, 2192-2195.

Shoseyov, O., Hamamoto, T., Foong, F. \& DoI, R. H. (1990). Cloning of Clostridium cellulovorans endo-1,4-beta-glucanase genes. Biochemical and Biophysical Research Communications 169, 667-672.

Sleat, R., Mah, R. A. \& Robinson, R. (1984). Isolation and characterization of an anaerobic, cellulolytic bacterium, Clostridium cellulovorans sp. nov. Applied and Environmental Microbiology 48, 8893.

Taylor, K. A., Crosby, B., McGavin, M., Forsberg, C. W. \& ThOMAS, D. Y. (1987). Characteristics of the endoglucanase encoded by a cel gene from Bacteroides succinogenes expressed by Escherichia coli. Applied and Environmental Microbiology 53, 41-46.
Wong, W. K. R., Gerhard, B., Guo, Z. M., Kilbern, D. G., WARREN, R. A. J. \& MilleR, R. C., JR (1986). Characterization and structure of an endoglucanase gene cenA of Cellulomonas fimi. Gene 44, 315-324.

Wood, W. A. \& ScotT, T. K. (1988). Methods for measuring cellulase activities. Methods in Enzymology 160, 87-112.

Wu, J. H. D. \& Demain, A. L. (1988). Proteins of the Clostridium thermocellum cellulase complex responsible for degradation of crystalline cellulose. In Biochemistry and Genetics of Cellulose Degradation, pp. 117-131. Edited by J.-P. Aubert, P. Beguin \& J. Millet. San Diego: Academic Press.

ZAPPE, H., JoNeS, D. T. \& WoODS, R. R. (1986). Cloning and expression of Clostridium acetobutylicum endoglucanase, cellobiase and amino acid biosynthesis genes in Escherichia coli. Journal of General Microbiology 132, 1367-1372. 